\title{
The Changing Profile of Autopsies Caused by Oral Cancer in Slovakia, 2010-2019
}

\author{
Pavel Stukovsky ${ }^{1,2}$ (1), Martin Samohyli@
}

\begin{abstract}
'Institute of Public Policy, Faculty of Social and Economic Sciences, Comenius University in Bratislava, Slovakia. ${ }^{2}$ The Prognostic Institute, Slovak Academy of Sciences, Bratislava, Slovakia.

${ }^{3}$ Institute of Hygiene, Faculty of Medicine, Comenius University in Bratislava, Slovakia.
\end{abstract}

Correspondence: Pavel Stukovsky, Institute of Public Policy, Faculty of Social and Economic Sciences, Comenius University in Bratislava, Mlynské luhy 4, 82105 Bratislava, Slovakia. E-mail: pavel.stukovsky@fses.uniba.sk

Academic Editor: Alidianne Fábia Cabral Cavalcanti

Received: 05 December 2020 / Review: 19 January 2021 / Accepted: 16 March 2021

How to cite: Stukovsky P, Samohyl M. The changing profile of autopsies caused by oral cancer in Slovakia, $2010-2019$. Pesqui Bras Odontopediatria Clín Integr. 202 1; 21 :e0256. https://doi.org/10.1590/pboci.2021.113

\begin{abstract}
Objective: To analyse the mortality rate and autopsy rate of oral cancer (malignant neoplasms of lip, oral cavity and pharynx) over a ten-year period. The percentage change of autopsy rate of oral cancer will be evaluated. Material and Methods: The study sample was divided into two age sub-categories: 1) patients who died of oral cancer and were autopsied in a period 2010-2014 and 2) patients who died of oral cancer and were autopsied in a period 2015-2019. Data from oral cancer death patients $(n=6,313)$ and autopsy patients caused oral cancer $(\mathrm{n}=251)$ between 2010-2019 were obtained from the Statistical Office of the Slovak Republic. The percentage change of autopsy rate was evaluated by Chi-squared test. Statistical significance was set at p-value $<0.05$. Results: The highest autopsy rate of malignant neoplasms of lip, oral cavity and pharynx was found in 2017 (4.1\%). It was observed growing trendy of autopsy rate of malignant neoplasms of lip, oral cavity and pharynx in the period 2010-2019 $\left(\mathrm{R}^{2}=0.059\right)$. It was found decrease of percentage change of autopsy rate in malignant neoplasm of pyriform sinus (-75.3\%). A significant increase of percentage change of autopsy rate was found in malignant neoplasm of tonsil $(216.1 \%$; $=0.021)$. Conclusion: This study provides one of the larger epidemiology overviews of oral cancer autopsies presented so far in Slovakia.
\end{abstract}

Keywords: Forensic Medicine; Vital Statistics; Mortality; Mouth Neoplasms. 


\section{Introduction}

Global, oral cancer is the $11^{\text {th }}$ most common malignant neoplasms [1] and it is becoming a public health problem [2,3]. Worldwide, cancer of salivary glands, hypopharynx, oropharynx, larynx, lip and oral cavity are the $28^{\text {th }}, 25^{\text {th }}, 24^{\text {th }}, 21^{\text {st }}, 16^{\text {th }}$ most common cancers, respectively [4].

According to the latest data (2018), the highest incidence of cancer of the lip and oral cavity had Papua New Guinea (20.4 per 100,000; Slovakia 6.1 per 100,000), larynx cancer had Cuba (8.9 per 100,000; Slovakia 4.2 per 100,000), oropharynx cancer had Hungary (4.7 per 100,000; Slovakia 3.5 per 100,000), hypopharynx cancer had Bangladesh (5.1 per 100,000; Slovakia 2.3 per 100,000), salivary gland cancer had Sweden (3.0 per $100,000)[4]$.

The autopsy (ultimate diagnostic test) [5] has fulfilled different purposes, including to medical science (education, research, prostheses and transplantation), medical care (total patient care, quality assurance, diagnostic-related groups), the family (understanding and counselling the life cycle) and society (forensic issues, vital statistics, public health) [6].

The analysis of the autopsy rate of oral cancer is absent in scientific studies. No scientific study has been available in the scientific database (PubMed and Scopus) using the keywords "oral cancer and autopsy rate" for the last 10 years. The issue of autopsy rate oral cancer has not been analysed in the world. We see the need to carry out this scientific study and its very added value for theory, science and practice.

The aim of the study is to analyse the mortality rate and autopsy rate of oral cancer (malignant neoplasms of lip, oral cavity and pharynx) over a ten-year period. The percentage change of autopsy rate of oral cancer between 2010-2014 and 2015-2019 will be evaluated.

\section{Material and Methods}

Sample

The study sample was divided into two age sub-categories: 1) Patients who died of oral cancer and were autopsied in a period 2010-2014 and 2) Patients who died of oral cancer and were autopsied in a period 2015-2019.

\section{Data Collection}

Data from oral cancer death patients $(n=6,313)$ and autopsy patients caused oral cancer $(n=251)$ between 2010-2019 were obtained from the Statistical Office of the Slovak Republic.

National mortality data about malignant neoplasm of lip (COO), malignant neoplasm of base of tongue (Co1), malignant neoplasm of other and unspecified parts of tongue (CO2), malignant neoplasm of gum (Co3), malignant neoplasm of floor of mouth (CO4), malignant neoplasm of palate (C05), malignant neoplasm of other and unspecified parts of mouth (CO6), malignant neoplasm of parotid gland (Co7), malignant neoplasm of other and unspecified major salivary glands (C08), malignant neoplasm of tonsil (Co9), malignant neoplasm of oropharynx (C10), malignant neoplasm of nasopharynx (C11), malignant neoplasm of pyriform sinus (C12) and malignant neoplasm of hypopharynx(C13) was analyzed.

\section{Statistical Analysis}

Data were processed by the statistical program SPSS, version 21 (IBM SPSS, Armonk, NY, USA). The percentage change of autopsy rate of oral cancer between 2010-2014 and 2015-2019 was evaluated by Chi-squared test. Statistical significance was set at p-value $<0.05$. 


\section{Results}

The basic characteristics of the sample are described in Table 1. The majority of autopsy rate was found in malignant neoplasm of other and unspecified major salivary glands (22.3\%) and the highest mortality was observed in malignant neoplasm of hypopharynx (1,314 deaths). The lowest autopsy rate (0.4\%) and mortality (85 deaths) was found in malignant neoplasm of lip in 2010-2019.

Table 1. Basic characteristics of the study sample.

\begin{tabular}{lcc}
\multicolumn{1}{c}{ Malignant Neoplasms of Lip, Oral Cavity and Pharynx } & Autopsy & Total Death \\
& $\mathrm{N}(\%)$ & $1 \%)$ \\
\hline Malignant Neoplasm of Lip & $28(11.2)$ & $557(8.8)$ \\
Malignant Neoplasm of Base of Tongue & $16(6.4)$ & $188(3.0)$ \\
Malignant Neoplasm of Other and Unspecified Parts of Tongue & $4(1.6)$ & $129(2.0)$ \\
Malignant Neoplasm of Gum & $14(5.6)$ & $602(9.5)$ \\
Malignant Neoplasm of Floor of Mouth & $6(2.4)$ & $194(3.1)$ \\
Malignant Neoplasm of Palate & $4(1.6)$ & $789(12.5)$ \\
Malignant Neoplasm of Other and Unspecified Parts of Mouth & $5(2.0)$ & $168(2.7)$ \\
Malignant Neoplasm of Parotid Gland & $56(22.3)$ & $96(1.5)$ \\
Malignant Neoplasm of Other and Unspecified Major Salivary Glands & $19(7.6)$ & $586(9.3)$ \\
Malignant Neoplasm of Tonsil & $36(14.3)$ & $1,217(19.3)$ \\
Malignant Neoplasm of Oropharynx & $4(1.6)$ & $212(3.4)$ \\
Malignant Neoplasm of Nasopharynx & $6(2.4)$ & $176(2.8)$ \\
Malignant Neoplasm of Pyriform Sinus & $52(20.7)$ & $1,314(20.8)$ \\
Malignant Neoplasm of Hypopharynx & 251 & 6,313 \\
\hline
\end{tabular}

Mortality rate (per 100,000 inhabitations) of malignant neoplasms of lip, oral cavity and pharynx in the period 2010-2019 can be seen in Figure 1A and Autopsy rate (\%) of malignant neoplasms of lip, oral cavity and pharynx in the period 2010-2019 can be seen in Figure 1B.

The highest autopsy rate of malignant neoplasms of lip, oral cavity and pharynx was found in 2017 (4.1\%). It was observed a growing trend of autopsy rate of malignant neoplasms of lip, oral cavity and pharynx in the period 2010-2019 $\left(\mathrm{R}^{2}=0.059\right)$.

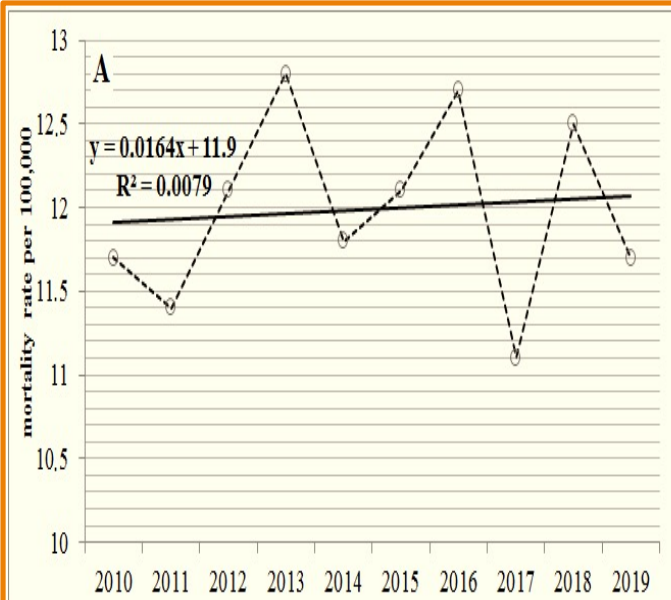

Figure 1. (A) Mortality rate (per 100,000 inhabitations) of malignant neoplasms of lip, oral cavity and pharynx in 2010-2019. (B) Autopsy rate (\%) of malignant neoplasms of lip, oral cavity and pharynx in

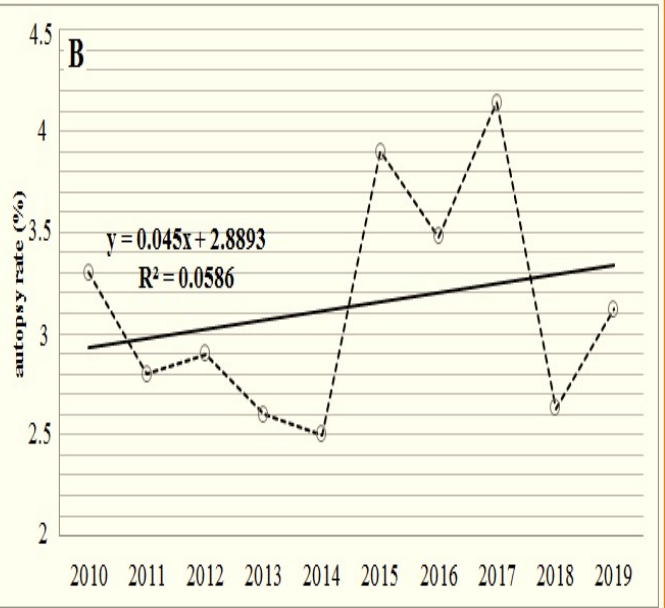

010-2019. 
Percentage change of autopsy rate of malignant neoplasms of lip, oral cavity and pharynx can be seen in Table 2. The highest percentage change of autopsy rate (266.1\%) was observed in malignant neoplasm of gum.

It was found a decrease of percentage change of autopsy rate in malignant neoplasm of pyriform sinus (75.3\%) between the period 2010-2014 and the period 2015-2019. A significant increase of percentage change of autopsy rate was found in malignant neoplasm of tonsil (216.1\%; p=0.021) between 2010-2014 and 20152019.

Table 2. Percentage change of autopsy rate of malignant neoplasms of lip, oral cavity and pharynx.

\begin{tabular}{|c|c|c|c|}
\hline \multirow[b]{2}{*}{ Malignant Neoplasms of Lip, Oral Cavity and Pharynx } & \multicolumn{3}{|c|}{ Autopsy Rate } \\
\hline & $\begin{array}{c}\text { 2010-2014 } \\
\%\end{array}$ & $\begin{array}{c}2015-2019 \\
\%\end{array}$ & $\begin{array}{c}\text { Percentage Change } \\
\%\end{array}$ \\
\hline Malignant Neoplasm of Lip 2010 & 2.85 & 0 & - \\
\hline Malignant Neoplasm of Base of Tongue & 4.29 & 5.64 & 31.5 \\
\hline Malignant Neoplasm of Other and Unspecified Parts of Tongue & 2.2 & 1.84 & -16.4 \\
\hline Malignant Neoplasm of Gum & 1.18 & 4.32 & 266.1 \\
\hline Malignant Neoplasm of Floor of Mouth & 1.27 & 3.11 & 144.9 \\
\hline Malignant Neoplasm of Palate & 3.13 & 3.06 & -2.2 \\
\hline Malignant Neoplasm of Other and Unspecified Parts of Mouth & 2.22 & 2.04 & -8.1 \\
\hline Malignant Neoplasm of Parotid Gland & 2.15 & 4 & 86.0 \\
\hline Malignant Neoplasm of Other and Unspecified Major Salivary Glands & 6.67 & 3.92 & -41.2 \\
\hline Malignant Neoplasm of Tonsil & 1.61 & 5.09 & $216.1^{*}$ \\
\hline Malignant Neoplasm of Oropharynx & 2.67 & 3.24 & 21.3 \\
\hline Malignant Neoplasm of Nasopharynx & 2.42 & 1.14 & -52.9 \\
\hline Malignant Neoplasm of Pyriform Sinus & 5.15 & 1.27 & -75.3 \\
\hline Malignant Neoplasm of Hypopharynx & 3.3 & 4.06 & 23.0 \\
\hline
\end{tabular}
" $\mathrm{p}=0.021$.

\section{Discussion}

In our study, we were limited to available scientific epidemiology autopsy studies. It was observed a growing trend of autopsy rate of oral cancer in the period 2010-2019. We can explain the trend with an effort to verify whether the healthcare was provided by lege artis procedure (for the purpose of verifying diseases or treatments). Bearing into the mind opinion of some medical professionals, autopsies are not needed because diagnostic with modern medical methods is improving. This is a reason why the total number of performed autopsies in most developed countries is decreasing [7].

The autopsy can be considered as one of the main indicators in monitoring and evaluating the quality of provided healthcare. It is also important for analysing causes of deaths or for assessing in the health status of population. The autopsy is also considered one of the basic elements in increasing the accuracy of important statistics and for obtaining reliable information in epidemiology. The autopsy is an invaluable basis for solving medical and legal issues, especially in case of suspicion of doubts in diagnostic or therapeutic procedures, which further contributes to improving the quality of health care in the future [7].

According to Burton et al. [8], of 250 malignant cancers autopsy diagnosed, $44 \%$ were misdiagnosed or undiagnosed.

According to Slovak law, an autopsy is also required in case that death could be caused by violence, including suicide. An increased incidence of suicide may contribute to an increased autopsy rate of oral cancer. According to Misono et al. [9], analyzing incidence rate of suicide in 3.594 .750 cancer patients was found for a sex-, race-, and age-adjusted rate of 31.4/100,000 suicides (in contrast, in the general population was suicide rate 16.7/100,000). Other studies have analyzed and identified increased suicide rates among cancer patients $[10,11]$. The Healthcare surveillance authority (in Slovak "Úrad pre dohl'ad nad zdravotnou starostlivost'ou") is 
responsible for all activities, which are connected with autopsies, including laboratory examination methods (histology, toxicology, histochemistry, immunohistochemistry, serology). According to the Slovak laws, the Healthcare surveillance authority has special departments of pathological anatomy and forensic medicine. Those departments are responsible for indicated autopsies, thus contributing to the supervision of the quality of health care provision. They are also providing objective data for the analysis of the causes of death and the assessment of the health status of the population. They actively contribute to improving the quality of diagnostics and improving medical and preventive care, especially in preventing unusual and unexpected deaths due to illnesses and fatal injuries [12].

\section{Conclusion}

It was observed a growing trend of autopsy rate of malignant neoplasms of lip, oral cavity and pharynx in the period 2010-2019. A significant increase of percentage change of autopsy rate was found in malignant neoplasm of tonsil. The present study provided one of the larger epidemiology overviews of oral cancer autopsies presented so far in Slovakia.

\section{Authors' Contributions}

$\begin{array}{lll}\text { PS } & \text { (D) https://orcid.org/0000-0001-8395-4835 } & \begin{array}{l}\text { Conceptualization and Writing - Original Draft. } \\ \text { Conceptualization, Methodology, Formal Analysis, Investigation and Writing - Review and } \\ \text { ES }\end{array} \\ \text { All autho hors declare that they contributed to critical review of intellectual content and approval of the final version to be published. }\end{array}$

\section{Financial Support}

None.

\section{Conflict of Interest}

The authors declare no conflicts of interest.

\section{Data Availability}

The data used to support the findings of this study can be made available upon request to the corresponding author.

\section{References}

[1] Ghantous Y, Abu Elnaaj I. Global Incidence and Risk Factors of Oral Cancer. Harefuah 2017; 156(10):645-9.

[2] de Sousa RIM, de Sousa RTA, Godoy GP, Cavalcanti AL, Nonaka CFW, Alves PM. Knowledge of Brazilian dentists about oral cancer. Pesqui Bras Odontopediatria Clin Integr 2016; 16(1):177-84. https://doi.org/10.4034/PBOCI.2016.161.19

[3] Ahmad P, Arshad AI, Jehangir M, Mahmood R, Shaikh GM, Alam MK, et al. Association of socio-demographic and clinicopathological risk factors with oral cancers: a 19-year retrospective study. Pesqui Bras Odontopediatria Clin Integr 2021; 21 :e0037. https://doi.org/10.1590/pboci.2021.010

[4] World Cancer Research Fund. Mouth, pharynx \& larynx cancer statistics. Cancers of the lip and oral cavity are the 16th most common cancers worldwide. 2018. Available from: https://www.wcrf.org/dietandcancer/cancertrends/mouth-pharynx-larynx-cancer-statistics. [Accessed on November 3, 2020].

[5] Goldman L. Autopsy 2018: Still necessary, even if occasionally not sufficient. Circulation 2018; 137(25):2686-8. https://doi.org/10.1161/CIRCULATIONAHA.118.033236

[6] Buja LM, Barth RF, Krueger GR, Brodsky SV, Hunter RL. The importance of the autopsy in medicine: perspectives of pathology colleagues. Acad Pathol 2019; 6:2374289519834041. https://doi.org/10.1 177/2374289519834041

[7] Sidlo J. Forensic Medicine: Autopsy. Bratislava: Comenius University in Bratislava; 2020. [In Slovakia].

[8] Burton EC, Troxclair DA, Newman III WP. Autopsy diagnoses of malignant neoplasms: how often are clinical diagnoses incorrect? JAMA 1998; 280(14):1245-8. https://doi.org/10.1001/jama.280.14.1245

[9] Misono S, Weiss NS, Fann JR, Redman M, Yueh B. Incidence of suicide in persons with cancer. J Clin Oncol 2008; 26(29):4731-8. https://doi.org/10.1200/JCO.2007.13.8941. 
[10] Björkenstam C, Edberg A, Ayoubi S, Rosén M. Are cancer patients at higher suicide risk than the general population? Scand J Public Health 2005; 33(3):208-14. https://doi.org/10.1080/1403494041 0019226

[11] Innos K, Rahu K, Rahu M, Baburin A. Suicides among cancer patients in Estonia: a population-based study. Eur J Cancer 2003; 39(15):2223-8. https://doi.org/10.1016/s0959-8049(03)00598-7

[12] Health Care Surveillance Authority. Performing an autopsy. Available from: www.udzs-sk.sk/vykonavanie-pitvy. [Accessed on November 3, 2020]. [In Slovakia]. 